\title{
Macrosomia Predictors in Infants Born to Cuban Mothers with Gestational Diabetes
}

\author{
Jeddú Cruz MD MS, Raiden Grandía DVM MS, Liset Padilla MD, Suilbert Rodríguez MD, Pilar Hernández MD, \\ Jacinto Lang MD, Antonio Márquez-Guillén MD PhD
}

\begin{abstract}
INTRODUCTION Fetal macrosomia is the most important complication in infants of women with diabetes, whether preconceptional or gestational. Its occurrence is related to certain maternal and fetal conditions and negatively affects maternal and perinatal outcomes. The definitive diagnosis is made at birth if a newborn weighs $>4000 \mathrm{~g}$.
\end{abstract}

OBJECTIVE Identify which maternal and fetal conditions could be macrosomia predictors in infants born to Cuban mothers with gestational diabetes.

METHODS A case-control study comprising 236 women with gestational diabetes who bore live infants ( 118 with macrosomia and 118 without) was conducted in the América Arias University Maternity Hospital, Havana, Cuba, during 2002-2012. The dependent variable was macrosomia (birth weight $>4000 \mathrm{~g}$ ). Independent maternal variables included body mass index at pregnancy onset, overweight or obesity at pregnancy onset, gestational age at diabetes diagnosis, pregnancy weight gain, glycemic control, triglycerides and cholesterol. Fetal variables examined included third-semester fetal abdominal circumference, estimated fetal weight at $\geq 28$ weeks (absolute and percentilized by Campbell and Wilkin, and Usher and McLean

\section{INTRODUCTION}

Fetal macrosomia (birth weight $>4000 \mathrm{~g}$ at term) is the most important complication in newborns of mothers with diabetes mellitus, whether preconceptional or gestational (diagnosed during pregnancy, especially after 24 weeks). This complication is usually associated with other problems in gestation and labor, the most important being birth trauma, sepsis, and respiratory, cardiovascular, metabolic or hematologic disorders.[1,2]

Worldwide, the frequency of fetal macrosomia in infants of mothers with gestational diabetes (IMGD) is approximately $10 \%-30 \%$, and, among other things, reflects the quality of obstetrical and endocrinologic care received by women with gestational diabetes (GD) during pregnancy.[3,4] In Cuba, this complication occurs in approximately $12 \%-20 \%$ of IMGDs.[5,6]

Quality prenatal care during pregnancy (including quality primary care) makes prevention of macrosomia in IMGDs possible by ensuring early detection of related conditions. There is evidence that fetal macrosomia in IMGDs is generally associated with certain maternal conditions, such as previous macrosomic child, older age, initial overweight or obesity, excess weight gain during pregnancy, late diagnosis of GD, poor glycemic control, hypertriglyceridemia and prolonged pregnancy.[4,6,7]

The diagnosis of fetal macrosomia in IMGDs should be done as early as possible, that is, at about 26 weeks' gestation, to begin early therapy and thereby minimize risk of poor maternal and perinatal outcomes. Early diagnosis of fetal macrosomia is also curves). Chi square was used to compare continuous variables (proportions) and the student $t$ test $(X \pm S D)$ for categorical variables, with significance threshold set at $p<0.05$. ORs and their $95 \% \mathrm{Cls}$ were calculated.

RESULTS Significant differences between cases and controls were found in most variables studied, with the exception of late gestational diabetes diagnosis, total fasting cholesterol and hypercholesterolemia. The highest OR for macrosomia were for maternal hypertriglyceridemia (OR 4.80, Cl 2.34-9.84), third-trimester fetal abdominal circumference $>75$ th percentile (OR 7.54, Cl 4.04-14.06), and estimated fetal weight $>90$ th percentile by Campbell and Wilkin curves (OR 4.75, CI 1.42-15.84) and by Usher and McLean curves (OR 8.81, Cl 4.25-18.26).

CONCLUSIONS Most variables assessed were predictors of macrosomia in infants of mothers with gestational diabetes. They should therefore be taken into account for future studies and for patient management. Wide confidence intervals indicate uncertainty about the magnitude of predictive power.

KEYWORDS Fetal macrosomia, fetal diseases, gestational diabetes, risk factors, risk prediction, Cuba

the only course available when no previous mitigation of avoidable risk factors has been accomplished.[4,6,7]

Excessive growth in macrosomic IMGDs depends mainly on uneven increase in fetal abdominal circumference (FAC) and thoracic and biparietal diameter, resulting in a high thorax/head ratio. This is mainly due to excess subcutaneous fat accounting for $20 \%$ of the infant's body weight (compared to $12 \%$ in newborns of normal weight). In fact, during the last weeks of pregnancy, the fetus of a mother with GD usually deposits $50 \%-60 \%$ more fat than the fetus of a nondiabetic mother. On the other hand, the increased FAC also reflects enlarged abdominal organs, especially hepatomegaly (typical of the IMGD with macrosomia).[3,4] This has led some researchers to propose that IMGD fetal weight should be estimated from FAC determined by ultrasound (US), rather than from the weight estimate generated by US software. They believe this approach would provide a more sensitive measurement, which, depending on its value, could more accurately predict macrosomia.[3,8]

Fetal US has estimated $70 \%$ sensitivity and specificity for predicting macrosomia in newborns.[3] The mean error is $200 \mathrm{~g}$ for use of US for FAC measurement and fetal weight estimation for gestational age in specific curves or tables relating both fetal parameters. Periodic measurement of this US parameter must start at 26-28 weeks' gestation and be carried out at intervals of 21-30 days. US-determined FAC at the $>75$ th percentile at the beginning of the third trimester has been associated with fetal macrosomia in IMGDs.[3,8] 
The adverse effects of macrosomia on IMGDs are not only restricted to fetal and perinatal life but also extend to childhood, adolescence and adulthood. Macrosomic IMGDs generally remain overweight or obese during childhood and adolescence and are at high risk of hypertension, diabetes mellitus and metabolic syndrome during young adulthood, and of ischemic heart disease and atherosclerosis by middle age.[1,2]

Since most predictors of fetal macrosomia are modifiable, identifying them facilitates primary prevention of this GD complication and its associated adverse maternal and perinatal outcomes. Cuban studies on the subject are scarce, and FAC percentile assessment is not a part of routine obstetric practice in Cuba. Hence, this research aims to demonstrate the usefulness of this method for predicting fetal macrosomia in IMGDs, studying a group of Cuban women with GD and the value of the two curves used in Cuba to determine fetal weight percentile (Campbell and Wilkin[9] and Usher and McLean[10]).

The research hypothesis was that fetal macrosomia in IMGDs can be predicted by certain maternal risk factors (initial overweight or obesity, diagnosis of GD at $>30$ weeks, excess weight gain, inadequate glycemic control, hypertriglyceridemia and hypercholesterolemia) and fetal conditions (FAC $>75$ th percentile and weight $>90$ th percentile for gestational age at $\geq 28$ weeks). Therefore, the objective of this study was to identify which of these maternal (clinical and laboratory) and fetal (US) variables are predictors of fetal macrosomia in IMGDs.

\section{METHODS}

Type of study and participants A retrospective case-control study was carried out, based on administrative data, between October 2002 and December 2012 (inclusive) in the antenatal diabetes service of the América Arias University Maternity Hospital (HUGAA) in Havana, Cuba. The universe comprised 1243 women with GD who gave birth at this hospital during the study period (approximately $3.9 \%$ of all births during the period), and who resided in HUGAA catchment municipalities (Centro Habana, Habana Vieja, Cerro and Habana del Este).

Sample calculation Sample size calculation was based on the assumption of $70 \%$ prevalence of overweight or obesity at pregnancy onset in cases and $46 \%$ in controls.[11] We specified $90 \%$ power to detect an odds ratio of 2.74 with $\alpha<5 \%$. The estimated sample size needed was 90 patients each in case and control groups. Taking into account a $5 \%$ probability of nonresponse (related to missing data in clinical records), the final sample size was 96 per group. However, since that number did not differ greatly from the number of women with GD who had macrosomic infants in the study period, we decided to include all of them in the study. Hence the sample size was 118 in each group.

Selection of cases and controls Cases were all women with GD who gave birth to a live macrosomic infant during the study period. Controls were

Maternal

women with GD who gave birth to a live nonmacrosomic infant, each the next delivery following that of one of the cases. Women whose infants were twins or underweight were excluded from the controls.

Variables Continuous variables included initial body mass index (BMI, $\mathrm{kg} / \mathrm{m}^{2}$ ), gestational age at GD diagnosis (weeks), total pregnancy weight gain $(\mathrm{kg})$, average monitored blood glucose (mmol/L-mg/dL), fasting plasma triglycerides $(T G, \mathrm{mmol} / \mathrm{L}$, single determination), fasting plasma total cholesterol $(\mathrm{mmol} / \mathrm{L}$, single determination), third-trimester FAC $(\mathrm{mm})$, and fetal weight determined by FAC $(\mathrm{g})$. All variables, except weight by FAC, were categorized to create qualitative or categorical variables (Table 1).

Data collection Information was extracted from medical records of women with GD treated at HUGAA during the study period, which also included data from primary health care records.

Techniques and procedures The following procedures reflect HUGAA protocol during the study period (in present tense) and authors' analytic strategies (in past tense).

Initial nutritional assessment of pregnant women with GD uses $\mathrm{BMI}$ and the criteria of the Institute of Nutrition and Food Hygiene (INHA).[12]

GD diagnosis uses the National Comprehensive Diabetes Pregnancy Care Program criteria: $\geq 2$ fasting blood glucose tests of

Table 1: Variables

\begin{tabular}{l|l} 
Variable & Definition \\
\hline
\end{tabular}

Gestational age at GD diagnosis

Late GD diagnosis

Initial BMI

Initial overweight or obesity[12]

Pregnancy weight gain
Excess pelivery (kg)
Excess pregnancy weight gain[12] - in overweight or obese woman, $>12$
- in normal weight woman, $>16$
- in low-weight woman, $>18$

Mean monitored blood glucose

Inadequate glycemic control

Fasting TG

Hypertriglyceridemia

Total fasting cholesterol

Hypercholesterolemia

Fetal

Third trimester FAC

Elevated FAC

Continuous variable $(\mathrm{mmol} / \mathrm{L})$, average of last 6 weekly blood glucose levels

Weight by third trimester FAC[16] Continuous variable (g)

- $>90$ th percentile for gestational age $\geq 28$ weeks (Campbell and Wilkin curves)[9]

Excess estimated fetal weight

- $>90$ th percentile for gestational age $\geq 28$ weeks (Usher and McLean curves)[10]

Macrosomia

Birth weight $>4000 \mathrm{~g}[17]$

BMI: body mass index FAC: fetal abdominal circumference GD: gestational diabetes TG: triglycerides 
$\geq 5.6 \mathrm{mmol} / \mathrm{L}(100 \mathrm{mg} / \mathrm{mL})$ or blood glucose $\geq 7.8 \mathrm{mmol} / \mathrm{L}(140$ $\mathrm{mg} / \mathrm{dL}$ ) in a 2-hour 75-g oral glucose tolerance test.[13] To define early GD diagnosis, we chose an upper limit of 30 weeks' gestation, since it has been reported that GD must be diagnosed and therapy started before this gestational age to prevent macrosomia.[17]

Assessment of total pregnancy weight gain follows INHA criteria.[12]

Assessment of glycemic control is determined weekly with an electronic reflectometer (glucometer) (glucoDr, South Korea). To assess glycemic control, the last six weekly blood glucose levels were averaged; glycemic control was considered inadequate if mean monitored blood glucose was $>5.0 \mathrm{mmol} / \mathrm{L}(90 \mathrm{mg} / \mathrm{dL}$ (criterion of National Comprehensive Diabetes Pregnancy Care Program).[13]

Lipid assessment is considered normal if maximum fasting plasma TG of $\leq 3.39 \mathrm{mmol} / \mathrm{L}$ during the third trimester of pregnancy and total cholesterol $\leq 6.60 \mathrm{mmol} / \mathrm{L}$, both obtained from a single determination.[14]

FAC percentile assessment is determined by US in the third trimester of pregnancy, using an Aloka SSD 1100 (Japan) apparatus, with a $5 \mathrm{MHz}$ transducer. The Tamura and Sabbagha curve[16] was applied to assess whether FAC was elevated, with the 75th percentile chosen as the upper limit of normal.[8]

Calculation of fetal weight by FAC in the third trimester used the Campbell and Wilkin curve.[9]

Assessment of fetal weight percentile in the third trimester used both the Campbell and Wilkin[9] and the Usher and McLean[10] curves/tables of fetal weight percentiles for gestational age. The 90th percentile of fetal weight for gestational age was chosen in both cases as the upper limit above which fetal growth was considered excessive.[8]

Birth weight determined in newborns using a scale (ATOM, Japan). Macrosomia in the newborn was diagnosed according to the National Gynecology and Obstetrics Expert Group criterion: birth weight $>4000$ g.[15]

Data analysis and presentation Proportions (percentages) were estimated for analysis of qualitative variables; for quantitative ones, means and standard deviations (SD) were calculated. To determine differences between the cases and controls, the Pearson chi-square $\left(\mathrm{X}^{2}\right)$ was used for qualitative variables and the student $t$ test for quantitative. A statistical significance of $p$ $<0.05$ was specified.

Odds ratios (OR) were estimated with the corresponding $95 \%$ confidence intervals $(\mathrm{Cl})$ to estimate the effect size of independent variables on the dependent variable (macrosomia diagnosed at birth). Results for continuous variables were presented in a two-way contingency table, and those for categorical variables in a table of means, SD, and $p$ values.

Ethics Information obtained from medical records was kept confidential. The study was approved by HUGAA's scientific council and the research ethics committee of the National Endocrinology Institute.

\section{RESULTS}

Statistically significant differences between cases and controls were observed in the means for six of eight continuous variables, exceptions being initial BMI and fasting plasma cholesterol (Table 2).

Among categorical variables, only differences in late GD diagnosis and hypercholesterolemia failed to reach significance. The highest ORs were for excess estimated fetal weight (>90th percentile per Usher and McLean OR 8.81, 95\% Cl 4.25-18.26; >90th percentile per Campbell and Wilkin, OR 4.75, 95\% Cl 1.42-15.84), elevated FAC (OR 7.54, 95\% Cl 4.04-14.06), hypertriglyceridemia (OR $4.80,95 \% \mathrm{Cl} 2.34-9.84$ ) and excess pregnancy weight gain (OR $3.10,95 \% \mathrm{Cl} 1.72-5.57$ ). Initial maternal overweight or obesity, and inadequate glycemic control also had OR >2 (Table 3).

Table 2: Macrosomia prediction, continuous variables

\begin{tabular}{|c|c|c|c|c|}
\hline \multirow{3}{*}{ Variable } & \multicolumn{2}{|c|}{ Macrosomia } & \multirow{3}{*}{$\mathbf{T}$} & \multirow{3}{*}{ p Value } \\
\hline & Yes & No & & \\
\hline & Mean (SD) & Mean (SD) & & \\
\hline $\begin{array}{l}\text { Gestational age at GD diagnosis } \\
\text { (weeks) }\end{array}$ & $30.58(5.83)$ & $27.57(7.96)$ & 3.32 & 0.0010 \\
\hline Initial BMI $\left(\mathrm{kg} / \mathrm{m}^{2}\right)$ & $27.43(4.41)$ & $26.26(5.11)$ & 1.88 & 0.0615 \\
\hline Pregnancy weight gain $(\mathrm{kg})$ & $11.95(4.66)$ & $9.85(4.70)$ & 3.45 & 0.0007 \\
\hline $\begin{array}{l}\text { Mean monitored blood glucose } \\
(\mathrm{mmol} / \mathrm{L} \text { and } \mathrm{mg} / \mathrm{dL})\end{array}$ & $\begin{array}{r}5.21(0.89) \\
93.79(16.04)\end{array}$ & $\begin{array}{r}4.74(0.53) \\
85.41(9.52)\end{array}$ & 4.89 & $<0.0001$ \\
\hline Fasting TG (mmol/L) & $2.72(1.03)$ & $2.31(0.87)$ & 3.33 & 0.0010 \\
\hline Total fasting cholesterol (mmol/L) & $5.84(1.31)$ & $5.95(1.29)$ & -0.69 & 0.4901 \\
\hline Third-trimester FAC (mm) & $312.02(37.69)$ & $290.70(30.94)$ & 4.77 & $<0.0001$ \\
\hline Fetal weight by FAC (g) & $2686.44(725.94)$ & $2247.46(595.96)$ & 5.08 & $<0.0001$ \\
\hline $\begin{array}{l}\text { BMI: body mass index } \\
\text { GD: gestational diabetes }\end{array}$ & $\begin{array}{l}\text { tal abdominal cir } \\
\text { lycerides }\end{array}$ & erence & & \\
\hline
\end{tabular}

Table 3: Macrosomia prediction, categorical variables

\begin{tabular}{|c|c|c|c|c|c|c|c|c|}
\hline \multirow{3}{*}{ Variable } & \multicolumn{4}{|c|}{ Macrosomia } & \multirow{3}{*}{$\mathrm{X}^{2}$} & \multirow{3}{*}{$\mathbf{p}$} & \multirow{3}{*}{ OR } & \multirow{3}{*}{$\mathbf{C l}$} \\
\hline & \multicolumn{2}{|c|}{$\begin{array}{c}\text { Yes } \\
\mathrm{n}=\mathbf{1 1 8} \\
\end{array}$} & \multicolumn{2}{|c|}{$\begin{array}{c}\text { No } \\
n=118 \\
\end{array}$} & & & & \\
\hline & $n$ & $\%$ & $n$ & $\%$ & & & & \\
\hline Late GD diagnosis & 73 & 61.9 & 60 & 50.8 & 2.91 & 0.088 & 1.57 & $(0.94-52.63)$ \\
\hline Initial overweight or obesity & 83 & 70.3 & 54 & 45.8 & 14.63 & $<0.001$ & 2.81 & $(1.65-4.79)$ \\
\hline $\begin{array}{l}\text { Excess pregnancy weight } \\
\text { gain }\end{array}$ & 49 & 41.5 & 22 & 18.6 & 14.69 & $<0.001$ & 3.10 & $(1.72-5.57)$ \\
\hline Inadequate glycemic control & 61 & 51.7 & 34 & 28.8 & 12.84 & $<0.001$ & 2.62 & $(1.55-4.51)$ \\
\hline Hypertriglyceridemia & 39 & 33.1 & 11 & 9.3 & 19.90 & $<0.001$ & 4.80 & $(2.34-9.84)$ \\
\hline Hypercholesterolemia & 35 & 29.7 & 32 & 27.1 & 0.19 & 0.6649 & 1.13 & $(0.65-1.99)$ \\
\hline $\begin{array}{l}\mathrm{FAC}>75 \text { th percentile in third } \\
\text { trimester }\end{array}$ & 66 & 55.9 & 17 & 14.4 & 44.62 & $<0.001$ & 7.54 & $(4.04-14.06)$ \\
\hline $\begin{array}{l}\text { Fetal weight }>90 \text { th percentile } \\
\text { (Campbell and Wilkin) }\end{array}$ & 13 & 11.0 & 3 & 2.5 & 6.70 & 0.0096 & 4.75 & $(1.42-15.84)$ \\
\hline $\begin{array}{l}\text { Fetal weight }>90 \text { th percentile } \\
\text { (Usher and McLean) }\end{array}$ & 108 & 91.5 & 65 & 55.1 & 40.40 & $<0.001$ & 8.81 & $(4.25-18.26)$ \\
\hline
\end{tabular}

FAC: fetal abdominal circumference GD: gestational diabetes 


\section{DISCUSSION}

The results for late GD diagnosis do not concur with those of some authors. For example, Szymańska demonstrated that when GD diagnosis is made at $24-28$ weeks, it is associated with decreased prevalence of macrosomia, compared to later diagnosys.[18] Torres estimated a relative risk (RR) of macrosomia of 2.123 at $>32$ weeks.[6] García found that $75.6 \%$ of women with a macrosomic newborn had GD diagnosed at $>20$ weeks;[19] Cruz found $84 \%$ had GD diagnosis at $>30$ weeks[11] and $77.5 \%$ at $>32$ weeks. [7] However, Dang found no statistically significant difference between women with and without a macrosomic infant, regarding GD diagnosis at $<30$ versus $\geq 30$ or $<32$ versus $\geq 32$ weeks, which agrees with our results.[20] The lack of statistical difference between cases and controls is likely due to the fact that in both groups, more than half were diagnosed with GD after 30 weeks' gestation.[13] In Cuba, an oral glucose tolerance test for GD diagnosis is done at 28-32 weeks (rather than at 24-28 weeks, as in some countries), which explains why so many are diagnosed late by the 30 -week criterion.

Initial overweight or obesity was associated with fetal macrosomia in IMGDs in our research. This finding was not unexpected, since obese women, even without GD, have more children with macrosomia than those who begin their pregnancy at normal weight. [21,22] Ouzounian[23] and Van Wootten and Turner[24] demonstrated that elevated BMI in early pregnancy is associated with macrosomia in IMGDs. Kerche[25] and Cypryk[26] reported that high $\mathrm{BMI}$ is a risk factor for macrosomia, with $\mathrm{OR}=1.83$ and $\mathrm{OR}=$ 2.38, respectively. Similar results have also been found in Cuban studies.[6,7,11,19,27]

We also found excessive weight gain during pregnancy associated with fetal macrosomia in IMGDs. This implies, at least theoretically, an excessive supply of nutrients to the fetus. This variable was a risk factor for IMGD macrosomia in studies by Tanir,[28] Ouzounian[23] and Kerche (OR = 1.79).[25] Cruz,[ 7] Park,[29] and Wong and Russell[30] also demonstrated that this variable is associated with neonatal macrosomia in the IMGDs.

Our findings indicated association between inadequate glycemic control and IMGD macrosomia. Hyperglycemia indicates excessive glucose supply to the fetus and fetal hyperinsulinism onset, directly responsible for IMGD macrosomia. This result is consistent with international[25,31] and national[7,11] studies that show poor glycemic control of GD associated with fetal macrosomia; however, this was not found by Lim.[32]

Hypertriglyceridemia was associated with IMGD fetal macrosomia. GD often induces dyslipidemia, characterized by a marked increase in TG and, consequently, free fatty acids, and very little or no plasma cholesterol. Several studies have shown that elevated maternal TG is associated with fetal macrosomia in IMGDs, $[7,31,33]$ consistent with our results. This was not the case, however, in one study by Couch.[34]

Since maternal cholesterol during pregnancy serves predominantly to produce placental steroid hormones and not as a fetal nutrient, its association with macrosomia in IMGDs has been questioned, unlike TG. Our results for cholesterol are consistent with those of Cruz[7] and Whyte,[35] who found no association between maternal hypercholesterolemia and IMGD macrosomia.
FAC $>75$ th percentile for gestational age at $\geq 28$ weeks, was associated with fetal macrosomia in IMGDs, although the wide Cl 95\% range should be noted. FAC is the single US measurement most strongly correlated with birth weight and by far the most commonly used to determine fetal weight.[8,36] Schaefer-Graf reports that two US with FAC <90th percentile are enough to exclude the risk of IMGD macrosomia.[37] Schaefer-Graf,[38] Bochner,[39] and Tamura[40] found that FAC >90th percentile in the third trimester of pregnancy was significantly associated with fetal macrosomia in IMGDs. Kjos[41] reports a similar result, but with FAC >70th percentile.

In our study, fetal weight $>90$ th percentile for gestational age $\geq 28$ weeks, both by Campbell and Wilkin and by Usher and McLean curves, was associated with fetal macrosomia in IMGDs. This has been demonstrated in other studies.[7,18,39,42,43] Nelson found the association for a fetal weight $>75$ th percentile.[43] García,[19] Tamura[40] and Wyse[44] for >90th percentile and Cruz for $>97$ th percentile.[7] However, Vedavathi[45] found no correlation between FAC and fetal weight with IMGD birth weight, and Johnstone[46] reported that fetal weight was not a predictor for macrosomia, inconsistent with our results. The findings of Vedavathi[45] and Johnstone[46] could be explained by the small sample of women with GD included in their studies.

Regarding results for the continuous variables, we found no significant BMI difference between groups, but the opposite occurred when this variable was studied as qualitative. This could be the effect of continuous variables' regression to the mean, which tends to dilute the observed effect. Dang and $\mathrm{Gu}$, on the other hand, found statistically significant differences in initial BMI between groups of macrosomic and nonmacrosomic IMGDs ( $p$ $=0.000$ and $p=0.008$, respectively). $[20,47]$ However, unlike us, Dang[20] found no statistically significant difference $(p=0.850)$ between the groups for mean blood glucose control.

Since macrosomia is the most frequent complication in IMGDs and the source of almost all their other complications (traumatic, respiratory, cardiovascular, metabolic, hematologic and septic disorders), preventing its onset implies improving maternal and perinatal outcomes for women with GD. An early GD diagnosis (before 30 weeks of pregnancy) is one of the first requirements for achieving this goal.

In Cuba, this responsibility rests mainly with doctors in primary health care, who must identify pregnant women at risk of GD. However, they should also be capable of identifying which women with GD are more likely to have macrosomic infants. This can only be achieved if they are well acquainted with conditions associated with macrosomia in IMGDs. Many of these conditions or determinants are sociocultural, such as poor nutrition, addictions, inadequate schooling, low socioeconomic status and unemployment.[48] Lack of consistent information on these conditions in patients' medical records limited our ability to examine these associations. We do believe that primary care physicians are well positioned to pay close attention to these conditions, since theirs is a community-based practice, facilitating frequent personal contact with their patients. What's more, Cuban women have an average of 16 antenatal visits per pregnancy.[49]

Our univariate analysis suggests that some maternal conditions are risk factors for IMGD macrosomia, but this needs verification by multivariate analysis, adjusting for different covariates. A limitation 
was our sample size calculation without access to prevalence data on some of the less frequent conditions in the underlying population (e.g., gestational age at GD diagnosis, hypercholesterolemia), which may have restricted the study's ability to detect significance in the associations observed. Another limitation is not having taken into account newborns' sex, which influences birth weight.

The novelty of this study lies in identifying a defined percentile value for FAC and fetal weight (applying two of the tables/curves used in Cuba) as predictors of neonatal macrosomia in IMGDs. The caveat is that these are international curves (there are no Cuban ones), so the source and application populations are of limited comparability. Professionals caring for women with GD at different levels in Cuba's national health system should be aware of these specific percentile values of FAC and fetal weight, to intervene early to avoid macrosomia, the major complication in IMGDs.

\section{CONCLUSIONS}

Initial overweight or obesity in pregnancy, excess pregnancy weight gain, inadequate glycemic control, hypertriglyceridemia, and FAC $>75$ th percentile and fetal weight $>90$ th percentile for gestational age $\geq 28$ weeks, were significantly associated with macrosomia in IMGDs and can therefore be considered predictors of this complication. We recommend instructing physicians caring for women with GD, especially in primary health care, to consistently assess these macrosomia risk factors or predictors, to help prevent the serious complications associated with this frequent growth disorder in IMGDs. We also recommend larger studies on this subject, in which not only clinical variables and laboratory tests are assessed, but also sociodemographic factors. At the same time, it becomes clear that Cuban FAC and fetal weight tables should be developed to increase the sensitivity of IMGD macrosomia diagnosis. $-1 /$ -

\section{REFERENCES}

1. Hawdon JM. Babies born after diabetes in pregnancy: what are the short- and longterm risks and how can we minimise them? Best Pract Res Clin Obstet Gynaecol. 2011 Feb;25(1):91-104.

2. Mitanchez D, Burguet A, Simeoni U. Infants born to mother with gestational diabetes mellitus: mild neonatal effects, a long-term threat to global health. J Pediatr. 2014 Mar;164(3):445-50.

3. Cruz J, Hernández P, Yanes M, Isla A. La macrosomía en el embarazo complicado con diabetes. Rev Centroamer Obstet Ginecol. 2009 JanMar;14(1):5-10. Spanish.

4. Šegregur J, Buković D, Milinović D, Orešković S, Panelić J, Župić T, et al. Fetal macrosomia in pregnant women with gestational diabetes. Coll Antropol. 2009 Dec;33(4):1121-7.

5. Terrero Llago A, Venzant Massó M, Reyes Salazar IS, Hechavarría Rodríguez AA. Efecto de la diabetes gestacional sobre los resultados perinatales. MEDISAN [Internet]. 2005 [cited 2013 Dec];9(2). Available from: http://bvs.sld.cu/revis tas/san/vol9_2_05/san08205.htm. Spanish.

6. Torres González C, Hernández Barrios E, Moreno Torres J, Rodríguez-Cabrera A, Vázquez Martínez V. Factores de riesgo para macrosomía en recién nacidos hijos de madre con diabetes gestacional. MediSur [Internet]. 2006 [cited 2013 Dec];4(1). Available from: http://medisur.sld .cu/index.php/medisur/article/view/172/4859\#. Spanish.

7. Cruz Hernández J, Vargas Torres I, Hernández P, Yanes Quesada M, Isla Valdés A, Rimbao Torres G. Macrosomía neonatal y diabetes gestacional. Rev Centroamer Obstet Ginecol. 2010 OctDec;15(4):116-21. Spanish.

8. Neff KJ, Walsh C, Kinsley B, Daly S. Serial fetal abdominal circumference measurements in predicting normal birth in gestational diabetes mellitus. Eur J Obstet Gynecol Reprod Biol. 2013 Sep;170(1):106-10.

9. Campbell $S$, Wilkin D. Ultrasonic measurement of fetal abdomen circumference in the estimation of fetal weight. $\mathrm{Br} \mathrm{J}$ Obstet Gynaecol. 1975 Sep;82(9):689-97.

10. Usher R, McLean F. Intrauterine growth of liveborn Caucasian infants at sea level: standards obtained from measurements in 7 dimensions of infants born between 25 and 44 weeks of gestation. J Pediatr. 1969 Jun;74(6):901-10.

11. Cruz Hernández J, Hernández García P, Yanes Quesada M, Rimbao Torres G, Lang Prieto J, Márquez Guillén A. Macrosomía neonatal en el embarazo complicado con diabetes. Rev Cubana Med Gen Integr [Internet]. 2008 Jul-Sep [cited
2013 Dec];24(3). Available from: http://scielo .sld.cu/scielo.php?script=sci arttext\&pid=S0864 $-21252008000300006 \&$ Ing=es. Spanish

12. Águila S, Breto A, Cabezas E, Delgado JJ, Santisteban S, editors. Nutrición en el embarazo. In: Obstetricia y perinatología. Diagnóstico y tratamiento. Havana: ECIMED; 2013. p. 77-106. Spanish.

13. Águila S, Breto A, Cabezas E, Delgado JJ, Santisteban S, editors. Diabetes y embarazo. In: Obstetricia y perinatología. Diagnóstico y tratamiento. Havana: ECIMED; 2013. p. 306-21. Spanish.

14. Klajnbard A, Szecsi PB, Colov NP, Andersen MR, Jørgersen M, Bjørngaard B, et al. Laboratory reference intervals during pregnancy, delivery and the early postpartum period. Clin Chem Lab Med. 2010 Feb;48(2):237-48.

15. Águila S, Breto A, Cabezas E, Delgado JJ, Santisteban S, editors. Distocia de hombros. In: Obstetricia y perinatología. Diagnóstico y tratamiento. Havana: ECIMED; 2013. p. 269-72. Spanish.

16. Tamura RK, Sabbagha RE. Percentile ranks of sonar fetal abdominal circumference measurements. Am J Obstet Gynecol. $1980 \mathrm{Nov}$ 1;138(5):475-9

17. Shushan A, Ezra Y, Samueloff A. Early treatment of gestational diabetes reduces the rate of fetal macrosomia. Am J Perinatol. 1997 May;14(5):253-6.

18. Szymańska M, Bomba-Opoń DA, Celińska AM, Weilgoś M. [Diagnostic of gestational diabetes mellitus and the prevalence of LGA (Large for Gestational Age)]. Ginekol Pol. 2008 Mar;79(3):177-81. Polish.

19. García León L, Romero OL, Medina Landeta R, Hernández Cabrera J. Macrosomía fetal en la diabetes mellitus gestacional. Su relación con los factores de riesgo. Rev Méd Electrón [Internet]. 2007 [cited 2013 Dec];29(6). Available from: http://www.revmatanzas.sld.cu/revista $\% 20$ medica/ano\%202007/vol6\%202007/tema06 .htm. Spanish.

20. Dang K, Homko C, Reece EA. Factors associated with fetal macrosomia in offspring of gestational diabetic women. J Matern Fetal Med. 2000 Mar-Apr:9(2):114-7.

21. Briese $V$, Voight $M$, Hermanussen $M$, WittwerBackofen U. Morbid obesity: pregnancy risks, birth risks and status of the newborn. Homo. 2010 Feb;61(1):64-72.

22. Lapolla A, Bonomo M, Dalfrà MG, Parretti E, Mannino D, Mello G, et al. Prepregnancy BMI influences maternal and fetal outcomes in women with isolated gestational hyperglycaemia: a multicenter study. Diabetes Metab. 2010 Sep;36(4):265-70.

23. Ouzounian JG, Hernández GD, Korst LM, Montoro MM, Battista LR, Walden CL, et al. Pre-pregnancy weight and excess weight gain are risk factors for macrosomia in women with gestational diabetes. J Perinatol. 2011 Nov;31(11):717-21

24. Van Wootten W, Turner RE. The prevalence of macrosomia in neonates of gestational diabetic mothers: analysis of risk factors. J Acad Nutr Dietetics. 1999 Sep;99(9 Suppl):S132.

25. Rodrigues Lima Kerche LT, Abbade JF, Araújo Costa RA, Vieira Cunha Rudge M, de Mattos Paranhos Calderon I. [Fetal macrosomia risk factors in pregnancies complicated by diabetes or daily hyperglycemia]. Rev Bras Ginecol Obstet. 2005;27(10):580-7. Portuguese.

26. Cypryk K, Pertyńska-Marczewska M, Szymczak W, Zawadniak-Szalapska M, Wliczyński J, Lewiński A. [Overweight and obesity as common risk factors for gestational diabetes mellitus (GDM), perinatal macrosomy in offspring and type-2 diabetes in mother]. Przegl Lek. 2005;62(1):38-41. Polish

27. Álvarez Zapata D, Valdés Amador L, Santana Bacallao O, Lugo Alonso J. El exceso y el bajo peso corporal al nacimiento en hijos de madres con diabetes. Rev Cubana Obstet Ginecol. 2012;38(3):294-304. Spanish.

28. Tanir HM, Sener T, Gürer H, Kaya M. A ten-year gestational diabetes mellitus cohort at a university clinic of the mid-Anatolian region of Turkey. Clin Exp Obstet Gynecol. 2005;32(4):241-4.

29. Park JE, Park S, Daily JW, Kim SH. Low gestational weight gain improves infant and maternal pregnancy outcomes in overweight and obese Korean women with gestational diabetes mellitus. Gynecol Endocrinol. 2011 Oct;27(10):77581.

30. Wong VW, Russell $\mathrm{H}$. Weight gain during pregnancy in women with gestational diabetes: How little is too little? Diab Res Clin Pract. 2013 Nov;102(2):e32-4.

31. Zawiejska A, Wender-Ozegowska E, Brazert J, Sodowski K. Components of metabolic syndrome and their impact on fetal growth in women with gestational diabetes mellitus. J Physiol Pharmacol. 2008 Sep;59 Suppl 4:S5-18.

32. Lim EL, Burden T, Marshall SM, Davison JM, Blott MJ, Waught JSJ, et al. Intrauterine growth rate in pregnancies complicated by type 1, type 2 and gestational diabetes. Obstet Med. 2009 Mar;2(1):21-5. 
33. Yun Liu K, Chow JM, Sherry C. Early life obesity and diabetes: origins in pregnancy. Open $\mathrm{J}$ Endoc Metab Dis. 2013 Feb;3(1):1-12.

34. Couch SC, Philipson EH, Bendel RB, Wijendran V, Lammi-Keefe CJ. Maternal and cord plasma lipid and lipoprotein concentrations in women with and without gestational diabetes mellitus. Predictors of birth weight? J Reprod Med. 1998 Sep;43(9):816-22.

35. Whyte K, Kelly H, O'Dwyer V, Gibbs M, O'Higgins A, Turner MJ. Offspring birth weight and maternal fasting lipids in women screened for gestational diabetes mellitus (GDM). Eur J Obstet Gynecol Reprod Biol. 2013 Sep;170(1):67-70.

36. Gopinath S, Varalakshmi G, Manoj K, Rubiya Glycemic control and fetal abdominal circumference. Indian J Endocrinol Metab. 2012 Dec;16(Suppl 2):S445-6.

37. Shaefer-Graf UM, Wendt L, Sacks DA, Kilavuz Ö, Gaber B, Metzner S, et al. How many sonograms are needed to reliably predict the absence of fetal overgrowth in gestational diabetes mellitus pregnancies? Diabetes Care. 2011 Jan;34(1):39-43.

38. Schaefer-Graf UM, Kjos SL, Kilavuz Ö, Plagemann A, Brauer $M$, Dudenhausen JW, et al. Determinants of fetal growth at different periods of pregnancies complicated by gestational diabetes mellitus or impaired glucose tolerance. Diabetes Care. 2003 Jan;26(1):193-8.

39. Bochner CJ, Medearis AL, Williams J 3rd, Castro L, Hobel CJ, Wade ME. Early third-trimester ultrasound screening in gestational diabetes to determine the risk of macrosomia and labor dystocia at term. Am J Obstet Gynecol. 1987 Sep;157(3):703-8.

40. Tamura RK, Sabbagha RE, Depp R, Dooley SL, Socol ML. Diabetic macrosomia: accuracy of third trimester ultrasound. Obstet Gynecol. 1986 Jun;67(6):828-32.

41. Kjos SL, Schaefer-Graf U, Sardesi S, Peters RK, Buley A, Xiang AH, et al. A randomized controlled trial utilizing glycemic plus fetal ultrasound parameters versus glycemic parameters to determine insulin therapy in gestational diabetes with fasting hyperglycemia. Diabetes Care. 2001 Nov;24(11):1904-10.
42. Díaz Salazar M, López Peña JG, García de Yegüez M, Herrera A, Meléndez M, Salas K Cálculo de peso al nacer por ultrasonido en las embarazadas de alto riesgo. Salus [Internet] 2011 Dec [cited 2013 Dec];15(3):13-8. Available from: http://www.scielo.org.ve/pdf/s/v15n3/art06 .pdf. Spanish.

43. Nelson L, Wharton B, Grobman WA. Prediction of large for gestational age birth weights in diabetic mothers based on early third-trimester sonography. J Ultrasound Med. 2011 Dec;30(12):1625-8.

44. Wyse LJ, Jones M, Mandel F. Relationship of glycosylated hemoglobin, fetal macrosomia, and birthweight macrosomia. Am J Perinatol. 1994 Jul;11(4):260-2

45. Vedavathi KJ, Swamy RM, Shekharappa KR, Venkatesh G, Veerananna HB. Influence of gestational diabetes mellitus on fetal growth parameters. Int J Biol Med Res. 2011:2(3):832-4.

46. Johnstone FD, Prescott RJ, Steel JM, Mao JH, Chambers S, Muir N. Clinical and ultrasound prediction of macrosomia in diabetic pregnancy. $\mathrm{Br} \mathrm{J}$ Obstet Gynaecol. 1996 Aug;103(8):747-54.

47. Gu S, An X, Fang L, Zhang X, Zhang C, Wang $\mathrm{J}$, et al. Risk factors and long-term health consequences of macrosomia: a prospective study in Jiangsu Province, China. J Biomed Res. 2012 Jul;26(4):235-40

48. Ragnarsdottir LH, Conroy S. Development of macrosomia resulting from gestational diabetes mellitus: physiology and social determinants of health. Adv Neonatal Care. 2010 Feb;10(1):7-12.

49. Ministry of Public Health (CU). Infomed [Internet] Havana: Ministry of Public Health (CU); c2015. Entrevistas. Mantiene Cuba la más baja mortalidad infantil de su historia. 2015 Jan 3 [cited 2015 Jul 8]; [about 3 p.]. Available from: http://www.sld .cu/entrevista/2015/01/03/mantiene-cuba-la-mas -baja-mortalidad-infantil-de-su-historia. Spanish.

\section{THE AUTHORS}

Jeddú Cruz Hernández (Corresponding author: celsocruz@infomed.sld.cu), family physician and endocrinologist, with master's degrees in comprehensive women's health and atherosclerosis research. Associate professor, Medical University of Havana (UCMH); adjunct researcher, National Endocrinology Institute (INEN), Havana, Cuba.

Raiden Grandía Guzmán, veterinarian with master's degree in microbiology, National Laboratory Animal Production Center, Havana, Cuba.

Liset Padilla Ledesma, family physician and endocrinologist, Comandante Manuel Fajardo University Clinical-Surgical Hospital, Havana, Cuba.

Suilbert Rodríguez Blanco, family physician, Nguyen Van Troi University Polyclinic, Havana, Cuba.

Pilar Hernández García, physician specializing in clinical laboratory medicine, Marfán University Pediatric Hospital; associate professor, UCMH. Havana, Cuba.

Jacinto Lang Prieto, endocrinologist. Associate professor, UCMH; associate researcher, INEN Havana, Cuba.

Antonio Márquez-Guillén, endocrinologist with doctorate in medical sciences. Full and consulting professor, UCMH. Senior researcher and head, National Comprehensive Diabetes and Pregnancy Program, INEN, Havana, Cuba

Submitted: April 21, 2014

Approved for publication: July 14, 2015

Disclosures: None

\section{ERRATUM}

Llibre JdeJ, López AM, Valhuerdi A, Guerra M, Llibre-Guerra J, Sánchez YY, et al. Frailty, Dependency and Mortality Predictors in a Cohort of Cuban Older Adults, 2003-2011. MEDICC Rev. 2014 Jan;16(1):24-30.

Page 24, Introduction, first paragraph, line 2, "600,000 to 2 billion" should read "600 million to 2 billion." 